\title{
Prophylactic stage 1 elephant trunk for moderately dilated descending aorta in patients with predominantly proximal disease
}

\author{
Jay J. Idrees, MD, Eric E. Roselli, MD, Charles M. Wojnarski, MD, Ke Feng, BS, Muhammad Aftab, MD,
} Douglas R. Johnston, MD, Edward G. Soltesz, MD, MPH, Joseph F. Sabik III, MD, and Lars G. Svensson, MD, PhD

\section{ABSTRACT}

Objective: Staged elephant trunk (ET) repair is a commonly performed procedure for extensive aortic disease. A significant proportion of patients with predominantly proximal aortic pathology often have in addition a moderately dilated descending aorta $(<5 \mathrm{~cm})$ that can progress over time. Objectives were to characterize patients, determine completion rate after prophylactic stage 1 ET, and assess outcomes.

Methods: From 1992 to 2012, a total of 572 patients underwent stage 1 ET for degenerative aneurysm and dissection at Cleveland Clinic. Prophylactic stage 1 ET was performed in $117(20.5 \%)$ who had predominantly proximal disease $(5.5 \pm 1 \mathrm{~cm})$ with moderate dilation of the descending aorta $(4 \pm 0.6 \mathrm{~cm})$. Aortic pathology included: aneurysm $(\mathrm{n}=56[48 \%])$; chronic dissection $(\mathrm{n}=41$ $[35 \%])$; pseudoaneurysm $(\mathrm{n}=9[7.7 \%])$; penetrating ulcer $(\mathrm{n}=9[7.7 \%])$; and intramural hematoma $(\mathrm{n}=2[1.7 \%])$. Other diagnoses included connective tissue disorder (12 [10\%]); aortitis (20 [17\%]); bicuspid aortic valve (9 [7.6\%]); and previous type A dissection repair (27 [23\%]).

Results: Operative mortality was $0.8 \%$ ( 1 of 117 ). This patient suffered postoperative myocardial infarction and mesenteric ischemia, resulting in sepsis and death. Other complications included: stroke $(\mathrm{n}=7[6 \%])$; tracheostomy $(\mathrm{n}=6[5 \%])$; renal dialysis $(\mathrm{n}=4[3.3 \%])$; and reoperation for bleeding $(\mathrm{n}=7[6 \%])$. The mean follow-up time was $4 \pm 3$ years. Fifty-three $(45 \%)$ patients completed the stage 2 ET (open: 20 [38\%]; endovascular: 33 [62\%]) at a median interval of 6 months ( 9 days-10 years). The mean descending diameter increased from $4.1 \pm 0.6 \mathrm{~cm}$ to $5 \pm 1 \mathrm{~cm}$ at the time of stage 2 completion. In 11 patients, stage 2 was performed for acute aortic events. Estimated survival at 1, 5, and 8 years was $94 \%, 88 \%$, and $74 \%$, respectively.

Conclusions: Prophylactic ET for moderately dilated descending aorta is an effective strategy for staged repair, especially in patients with chronic dissection, connective tissue disorder, and aortitis. In addition, this approach can be beneficial for emergency treatment of late distal aortic complications. (J Thorac Cardiovasc Surg 2015;150:1150-7)

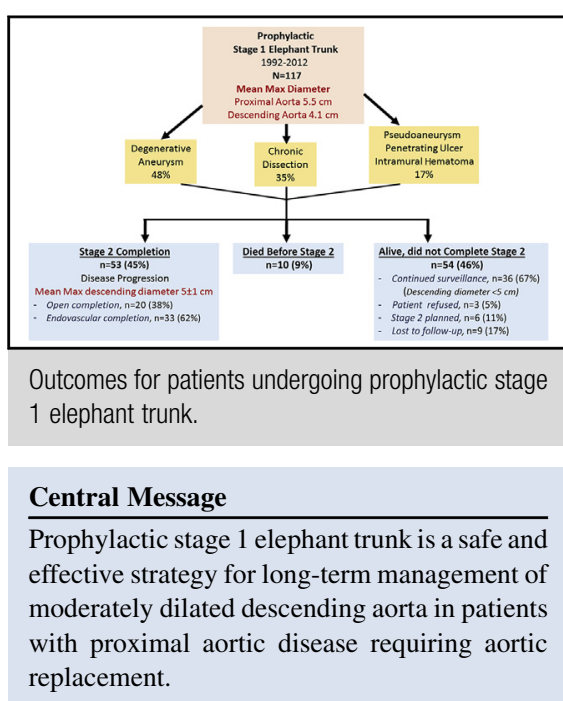

Perspective

Prophylactic stage 1 ET should be considered in patients with moderately dilated descending aorta, particularly with underlying connective tissue disorder, chronic dissection, or aortitis, who require aortic replacement for proximal disease. This approach is safe and effective and facilitates long-term management of disease progression in the untreated distal aorta and emergency treatment of distal aortic complications with endovascular ET completion.

See Editorial Commentary page 1158.
From the Department of Thoracic and Cardiovascular Surgery and Aortic Center, Heart and Vascular Institute, Cleveland Clinic, Cleveland, Ohio.

This study was supported in part by Judith Chew and John S. Chew and the Warden Foundation.

Read at the 95th Annual Meeting of The American Association for Thoracic Surgery, Seattle, Washington, April 25-29, 2015.

Received for publication May 7, 2015; revisions received July 14, 2015; accepted for publication July 22, 2015; available ahead of print Oct 1, 2015.

Address for reprints: Eric E. Roselli, MD, Cleveland Clinic, 9500 Euclid Ave/Desk J4-1, Cleveland, OH 44195-5108 (E-mail: roselle@ccf.org). 0022-5223/\$36.00

Copyright $₫ 2015$ Published by Elsevier Inc. on behalf of The American Association for Thoracic Surgery

http://dx.doi.org/10.1016/j.jtcvs.2015.07.077
Patients with extensive aortic aneurysm and dissection often require multiple aortic repairs for the treatment of progressive disease. A 2-stage treatment approach with a conventional elephant trunk (ET) procedure followed by a stage 2 distal repair is commonly used to manage these patients. ${ }^{1-4}$

Current guidelines recommend aortic replacement when maximum diameter is $\geq 5$ to $5.5 \mathrm{~cm}$ for the proximal aorta, and $\geq 5.5$ to $6 \mathrm{~cm}$ for the descending aorta, with or without high risk factors, respectively. ${ }^{5,6}$ In a substantial proportion of patients, the proximal aorta at the time of presentation is 


\section{Abbreviations and Acronyms \\ $\mathrm{EEC}=$ endovascular elephant trunk completion \\ ET $=$ elephant trunk}

large enough to mandate surgical replacement, but the descending aorta may be only moderately dilated, below the threshold for elective replacement. A very limited body of data is available to guide surgical strategy for these patients. We have increasingly performed replacement of the ascending aorta and arch, including a stage $1 \mathrm{ET}$, to address the most-diseased aorta and offer a prophylactic benefit if the descending aorta requires a later reintervention. Objectives of this study are to characterize these patients, and to assess the risks and benefits of placing a prophylactic stage $1 \mathrm{ET}$.

\section{METHODS \\ Patients}

From 1992 to 2012, a total of 572 patients underwent stage 1 ET for degenerative aneurysm and/or dissection at the Cleveland Clinic. For $117(20.5 \%)$ of these, who had a moderately dilated descending aorta $(<5 \mathrm{~cm})$ at the time of presentation, the stage 1 ET was performed prophylactically. The stage 1 ET was performed primarily to treat the ascending and arch pathology, but an ET graft was placed prophylactically into the moderately dilated descending aorta based on the presupposition that the patients would require a distal aortic intervention at a later point. The mean age was $63 \pm 13$ years, and additional descriptive details are included in Table 1 . The $\mathrm{R}$ programming statistical package ( $\mathrm{R}$ development Core Team, 2010) was used for analysis.

\section{Indications for Prophylactic Elephant Trunk}

The mean maximum aortic diameter at the time of prophylactic stage 1 ET was $5.5 \pm 1 \mathrm{~cm}$ for the proximal aorta, $4.6 \pm 0.8 \mathrm{~cm}$ for the arch, and $4 \pm 0.6 \mathrm{~cm}$ for the thoracic descending aorta. The descending diameter was $>4.5 \mathrm{~cm}$, but $<5 \mathrm{~cm}$ in $36(31 \%)$ patients, between 4.0 and $4.4 \mathrm{~cm}$ in $39(33 \%)$, and $<4 \mathrm{~cm}$ in $42(36 \%)$. Proximal aortic pathology at presentation included: degenerative aneurysm ( $\mathrm{n}=56[48 \%])$; chronic dissection with or without aneurysm ( $\mathrm{n}=41[35 \%])$; pseudoaneurysm after previous type A dissection repair $(n=9[7.7 \%])$; penetrating ulcer with or without saccular aneurysm $(\mathrm{n}=9$ [7.7\%]); and intramural hematoma $(\mathrm{n}=2[1.7 \%])$. Additionally, $11(9.4 \%)$ patients had a documented connective tissue disorder; $20(17 \%)$ had aortitis (defined as giant cells seen on histologic examination of the pathology specimen); and 9 $(7.7 \%)$ had a bicuspid aortic valve. Seven of the bicuspid valve patients had chronic dissection, and 2 patients had coarctationassociated descending aneurysms. The stage 1 ET was performed as a reoperation in $44(37 \%)$ patients, including 27 who had a history of previous acute type A dissection repair.

\section{Stage 1 and Stage 2 Repair Methods}

Ascending and total arch replacement was performed in all patients at the time of stage $1 \mathrm{ET}$, using deep hypothermic circulatory arrest, with or without brain perfusion. The arch anastomosis was performed either as a patch or with separate bypasses to the branch vessels. The distal ET anastomosis was constructed beyond, or proximal to, the left subclavian artery. ${ }^{3}$ In 4 patients with chronic dissection, an open fenestration of the dissection flap was performed at the time of prophylactic stage 1 ET to create a suitable distal landing zone for possible stent grafting during stage 2 .

Details of this procedure have been described elsewhere. ${ }^{7}$ In all patients, the distal portion of the ET graft was marked with large hemoclips to allow for radiographic visualization at the time of stage 2 completion if stent grafting is being contemplated. Patients receiving stent graft devices, or undergoing the frozen ET procedure, were not included in this series.

After the stage $1 \mathrm{ET}$, patients routinely underwent predischarge imaging to establish a baseline comparison for surveillance monitoring. The descending aorta was $<5 \mathrm{~cm}$ at the time of discharge in all patients. Three patients underwent the stage 2 ET during the same hospital admission; details are discussed in the Results section.

The stage 2 ET completion was performed in selected patients who developed progressive degeneration or acute complications of the untreated descending aorta during follow-up. This process was managed with either an open $(n=20)$ or endovascular $(n=33)$ approach. The open completion was performed through a left posterolateral thoracotomy, with partial left-atrium-to-femoral-artery cardiopulmonary bypass, active cooling, and cerebrospinal fluid drainage. Intercostal arteries were reimplanted when this approach was feasible. Open ET completion included replacement of the thoracoabdominal aorta in 5 patients.

The EEC was performed in a hybrid operating room. In most cases, EEC was performed under general anesthesia, but in a few selected patients with severe pulmonary disease, regional spinal anesthesia was used. The stent graft devices were usually delivered using a wire extending across the right brachial artery and 1 common femoral artery. The stent grafts were delivered via the illiofemoral system into the ET graft and deployed with $\geq 2$ stents of overlap between the stentgraft and the ET graft. Prophylactic cerebrospinal fluid drainage was performed for most patients. Additional details about the techniques used for both open ET completion and EEC are described elsewhere.,

\section{Concomitant Procedures}

Sixty-six concomitant procedures were performed in $58(50 \%)$ patients during the stage $1 \mathrm{ET}$, including aortic valve repair $(\mathrm{n}=7$ $[6 \%])$ or replacement $(\mathrm{n}=30[26 \%])$; coronary artery bypass grafting $(\mathrm{n}=17[15 \%])$; open distal fenestration $(\mathrm{n}=4[3.4 \%])$; root replacement $(\mathrm{n}=3[2.5 \%])$; atrial septal defect closure $(\mathrm{n}=2[1.7 \%])$; mitral valve repair $(\mathrm{n}=2[1.7 \%])$; and tricuspid valve repair $(\mathrm{n}=1$ $[8.4 \%])$.

\section{Follow-up}

All patients underwent computed tomography assessment before discharge and during scheduled follow-up outpatient visits, which typically occur within the first 6 months after an operation, and then annually. If renal function was preserved, patients received contrast, and in those who underwent EEC, a 3-phase protocol was used that included a noncontrast phase through the treated segment, and intravenous contrast scans through the chest, abdomen, and pelvis, timed for both arterial and delayed venous phases. All computed tomography scans were analyzed using 3-dimensional reconstruction software (TeraRecon, Inc, San Mateo, Calif) to assess graft patency, device integrity, endoleaks, and aortic morphology. The mean follow-up time was $4 \pm 3$ years; $39 \%$ of the patients were followed for $>5$ years, and $16 \%$ for $>8$ years.

\section{Outcome Definitions and Statistics}

Operative mortality was defined as death during hospitalization, or within 30 days of the procedure. Renal failure was defined as need for hemodialysis, and respiratory failure as need for reintubation or tracheostomy, postoperatively. Categoric variables are summarized using frequencies and percentages; continuous variables are summarized using 
TABLE 1. Patient characteristics, operative details

\begin{tabular}{|c|c|}
\hline Characteristic & Value $(n=117)$ \\
\hline Age (y) & $63 \pm 13$ \\
\hline Male & $54(46)$ \\
\hline Prior cardiac surgery & $44(38)$ \\
\hline Acute type A dissection repair & $27 / 44(61)$ \\
\hline Connective tissue disorder & $11(10)$ \\
\hline Aortitis & $20(17)$ \\
\hline Bicuspid aortic valve & $9(8)$ \\
\hline Hypertension & $91(77)$ \\
\hline Diabetes & $7(6)$ \\
\hline Chronic obstructive pulmonary disease & $31(26)$ \\
\hline History of cerebrovascular accident & $9(8)$ \\
\hline Congestive heart failure & $14(12)$ \\
\hline History of cancer & $11(9)$ \\
\hline Chronic renal failure & $9(8)$ \\
\hline Peripheral arterial disease & $4(4.2)$ \\
\hline \multicolumn{2}{|l|}{ Aortic morphology } \\
\hline Degenerative aneurysm & $55(47)$ \\
\hline Chronic dissection & $42(36)$ \\
\hline Pseudoaneurysm & $9(7.7)$ \\
\hline Penetrating ulcer & $9(7.7)$ \\
\hline Intramural hematoma & $2(1.7)$ \\
\hline \multicolumn{2}{|l|}{ Maximum diameter at stage 1 elephant trunk $(\mathrm{cm})$} \\
\hline Proximal aorta & $5.5 \pm 1$ \\
\hline Descending aorta & $4 \pm 0.6$ \\
\hline Maximum descending diameter at stage $2(n=54 ; 46 \%)$ & $5 \pm 1$ \\
\hline \multicolumn{2}{|l|}{ Operative details } \\
\hline Prophylactic stage 1 elephant trunk & $117(100)$ \\
\hline Concomitant procedures & $66(56)$ \\
\hline Aortic valve repair & $7(6)$ \\
\hline Aortic valve replacement & $30(26)$ \\
\hline Coronary artery bypass grafting & $17(15)$ \\
\hline Open distal fenestration & $4(3.4)$ \\
\hline Root replacement & $3(2.5)$ \\
\hline Atrial septal defect closure & $2(1.7)$ \\
\hline Mitral valve repair & $2(2.5)$ \\
\hline Stage 2 completion repair & $53(45)$ \\
\hline Open & $20(38)$ \\
\hline Endovascular & $33(62)$ \\
\hline \multicolumn{2}{|l|}{ Postoperative complications } \\
\hline \multicolumn{2}{|l|}{ Stage 1 elephant trunk } \\
\hline Mortality & $1(0.8)$ \\
\hline Stroke & $7(5.9)$ \\
\hline Tracheostomy & $6(5)$ \\
\hline Reoperation for bleeding & $7(5.9)$ \\
\hline Renal dialysis & $4(3.3)$ \\
\hline Stage 2 completion & $\mathrm{n}=53$ \\
\hline Mortality & $1(1.9)$ \\
\hline Stroke & $1(1.9)$ \\
\hline Reoperation for bleeding & $1(1.9)$ \\
\hline Transient paraparesis & $1(1.9)$ \\
\hline Renal dialysis & 0 \\
\hline
\end{tabular}

Values are $\mathrm{n}(\%)$, or mean $\pm \mathrm{SD}$.

median or mean \pm SD. Estimated survival and probability of stage 2 ET completion were determined using the Kaplan-Meier method. This study was approved by the Cleveland Clinic Institutional Review Board, with a waiver of any patient consent requirement.
TABLE 2. Timing and change in aortic diameter in various subgroups of patients who completed stage 2

\begin{tabular}{|c|c|c|c|c|}
\hline \multicolumn{5}{|c|}{ Maximum descending diameter $(\mathrm{cm})$} \\
\hline Variable & n $(\%)$ & Stage 1 & Stage 2 & $\begin{array}{c}\text { Interval to } \\
\text { stage } 2 \\
\text { (mo, median) } \\
\end{array}$ \\
\hline \multicolumn{5}{|l|}{ Indication stage 1} \\
\hline Aneurysm & $27(50)$ & $4.3 \pm 0.5$ & $5.1 \pm 1$ & 14.6 \\
\hline Chronic dissection & $18(34)$ & $4 \pm 0.7$ & $5.1 \pm 0.9$ & 5.4 \\
\hline $\begin{array}{l}\text { Unstable pathology } \\
\text { (intramural hematoma/ } \\
\text { ulcer/pseudoaneurysm) }\end{array}$ & $8(15)$ & $4 \pm 0.4$ & $4.7 \pm 1$ & 4.9 \\
\hline \multicolumn{5}{|l|}{ Underlying diagnosis } \\
\hline $\begin{array}{l}\text { Connective tissue } \\
\text { disorder }\end{array}$ & $8(15)$ & $3.9 \pm 0.8$ & $4.9 \pm 0.5$ & 4.9 \\
\hline Aortitis & $12(22)$ & $4.3 \pm 0.4$ & $5.3 \pm 1$ & 17.9 \\
\hline Remaining & $34(63)$ & $4.1 \pm 0.6$ & $4.9 \pm 1$ & 6.1 \\
\hline
\end{tabular}

\section{RESULTS \\ Outcomes After Prophylactic Stage 1 Elephant Trunk}

The operative mortality after stage 1 ET was $0.8 \%$ ( 1 of 117). This patient had chronic dissection and suffered postoperative myocardial infarction and mesenteric ischemia, resulting in sepsis and death from multiorgan failure on postoperative day 52. Other complications included: stroke $(\mathrm{n}=7[6.0 \%])$; tracheostomy for respiratory failure $(\mathrm{n}=6[5.1 \%])$; hemodialysis for renal failure $(\mathrm{n}=4[3.4 \%])$; and reoperation for bleeding $(\mathrm{n}=7[6.0 \%])$. Of the 7 patients who suffered postoperative stroke, 5 had extensive arch and descending aortic atheroma, with or without penetrating ulcers; 1 had a pseudoaneurysm with thrombus at the distal anastomosis of a previous type A repair; and 2 had a history of previous stroke. Axillary artery cannulation was used in only 3 of these patients, and antegrade brain perfusion was used in 1 .

\section{Stage 2 Elephant Trunk Completion}

Fifty-three $(45 \%)$ patients completed the stage 2 ET during a mean follow-up of 4 years (open: 20 [38\%]; endovascular: $33[62 \%]$ ), at a median interval of 6 months (9 days to 10 years). Stage 2 was completed within 3 months in $20 \%,>3$ months but $<1$ year in $45 \%$, and after 1 year in $35 \%$. Patients who completed stage 2 within the 3 -month period had urgent indications. Additional details regarding the timing of stage 2 completion and descending diameter according to diagnosis are summarized in Table 2 .

The stage 2 ET was completed during the same hospital admission in $3(2.5 \%)$ patients. One patient had an anastomotic leak from the suture line after stage $1 \mathrm{ET}$ and underwent emergency stage 2 EEC with endovascular coverage of the anastamosis. The second patient was diagnosed with a contained rupture of the mid-descending aorta distal to the ET graft, discovered on the predischarge 


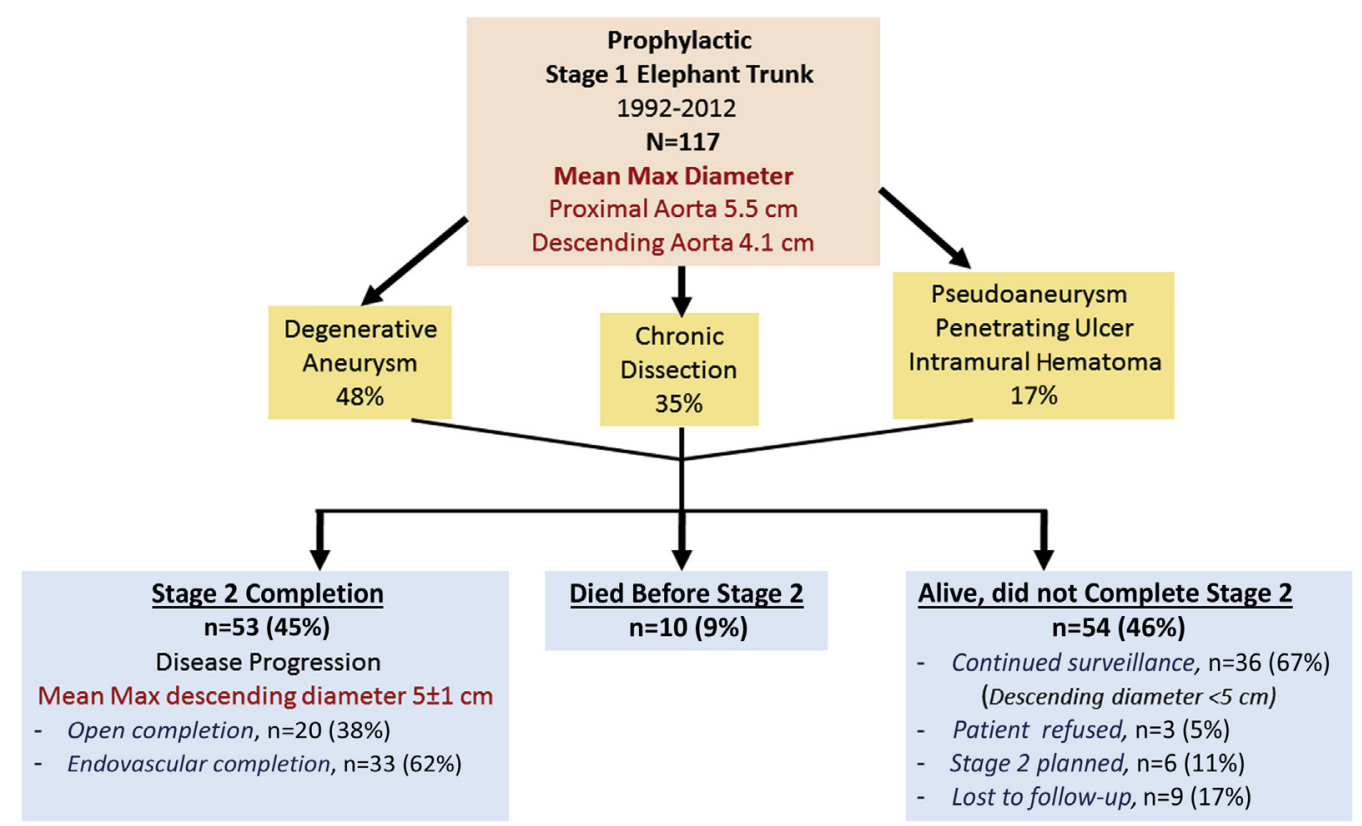

FIGURE 1. Fate of the prophylactic stage 1 elephant trunk; a consort diagram shows aortic characteristics and indications for prophylactic stage 1 elephant trunk and later elephant trunk completion. Reasons for noncompletion of stage 2 are listed.

computed tomography scan, and underwent emergency EEC. The third patient presented with symptomatic type $\mathrm{B}$ dissection, with extension into the arch and a 4-cm upper descending aorta. He developed rapid false lumen expansion, so a stage 2 EEC was completed during the same hospital admission. There were no spinal injuries or major complications after EEC in these patients.

Overall, in patients who completed stage 2 , the mean descending diameter increased from $4.1 \pm 0.6 \mathrm{~cm}$ to $5 \pm 1 \mathrm{~cm}$ at the time of stage 2 completion. In $11(20 \%)$ patients, stage 2 was performed for acute events including rupture or leak $(n=4)$, chronic dissection complicated by malperfusion $(\mathrm{n}=3)$, penetrating ulcer $(\mathrm{n}=2)$, pseudocoarctation of the previous ET $(\mathrm{n}=1)$, and rapid growth $(\mathrm{n}=1)$. The latter patient had Marfan syndrome with chronic dissection and presented with descending aortic growth of $5 \mathrm{~mm}$ in 2 months, with a maximum diameter of $4.7 \mathrm{~cm}$.

Of the $64(54 \%)$ patients who have not completed stage 2 , a total of $10(9 \%)$ died during follow-up. One patient had a new acute type $b$ dissection and presented at an outside facility. He was managed medically and transferred to Cleveland Clinic; unfortunately, this patient died as a result of complications of malperfusion. Another died of renal failure and hemolytic anemia; the cause of death is unknown in the remaining 8 patients. Nine patients were lost to follow-up, and 3 had significant growth of the descending aorta but refused additional surgery (Figure 1). In 6 patients, stage 2 is planned but not yet completed. The remaining 36 patients are on continued surveillance as the descending diameter is $<5 \mathrm{~cm}$ (mean: $4.1 \pm 0.8 \mathrm{~cm}$ ).

\section{Outcomes After Stage 2 Elephant Trunk Completion}

One patient died after open thoracoabdominal stage 2 ET completion (operative mortality: $1.9 \%$ [1 of 53]). This patient had previously undergone prophylactic stage 1 ET and presented 3 years later with a $6.4-\mathrm{cm}$ thoracic and thoracoabdominal aneurysm $(4.8 \mathrm{~cm}$ at the time of the first stage). The stage 2 operation was successfully completed, but the patient had a massive embolic stroke and died on postoperative day 2 . Other complications included transient paraparesis after endovascular completion $(\mathrm{n}=1[1.9 \%])$, and reoperation for bleeding after open completion $(\mathrm{n}=1$ $[1.9 \%])$, but no respiratory failure or new-onset renal failure.

\section{Survival and Probability of Elephant Trunk Completion}

The estimated survival after stage $1 \mathrm{ET}$ at 1,5 , and 8 years was $94 \%, 88 \%$, and $74 \%$, respectively (Figure 2). The probability of stage $2 \mathrm{ET}$ completion at 1,5 , and 10 years was $39 \%, 59 \%$, and $83 \%$, respectively (Figure 3 ).

\section{DISCUSSION}

The current guidelines are unclear regarding the optimal strategy for managing patients who require proximal aortic replacement with moderate distal disease. Based on our experience, prophylactic stage 1 ET seems to have a long-term benefit in patients who have a moderately dilated descending aorta, who require proximal aortic replacement, and pathology associated with diffuse disease. We demonstrated that prophylactic stage 1 ET can be performed 


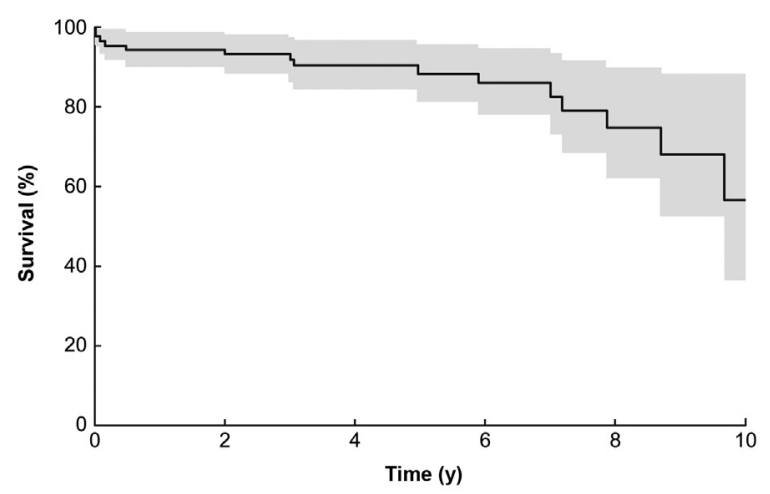

$\begin{array}{llllllllllll}\text { No. at Risk } & 117 & 85 & 73 & 64 & 53 & 44 & 35 & 26 & 17 & 10 & 4\end{array}$

FIGURE 2. Kaplan-Meier estimated survival after a stage 1 elephant trunk procedure. Confidence limits are equivalent to $\pm 1 \mathrm{SE}$.

safely. Nearly one half of patients required stage 2 repair, with a mean follow-up time of only 4 years; these repair procedures were performed safely as well. The estimated 8 -year survival was very good in a population of complex patients who had extensive aortic disease. In addition, the prophylactic placement of the ET proved to be useful in managing acute distal aortic complications that occurred in approximately $10 \%$ of patients who required emergency stage 2 completion.

The refinement of modern techniques and brain protection strategies during circulatory arrest have helped make total arch replacement and stage 1 ET repair safe in selected patients. Studies from high-volume centers on recent experience with total arch replacement have reported a mortality as low as $2 \%$, and it has been consistently $<10 \%$ even during reoperations. ${ }^{9-13}$ These encourraging results favor consideration for a more aggressive approach at the time of initial intervention that can offer long-term benefits in patients with extensive aortic disease.

All patients were considered to be at high risk for progressive degeneration, in particular those with chronic

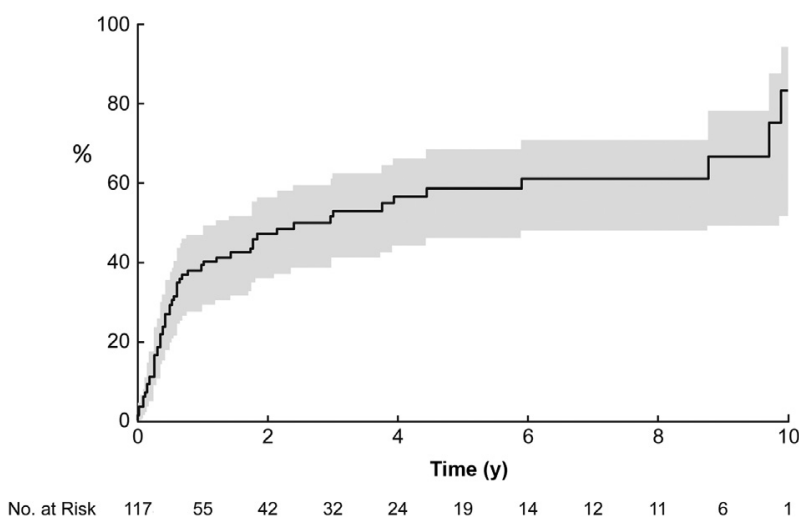

FIGURE 3. Probability of elephant trunk completion after prophylactic stage 1 elephant trunk procedure using the Kaplan-Meier method for estimation of cumulative incidence. Confidence limits are equivalent to $\pm 1 \mathrm{SE}$. dissection, connective tissue disorder, and aortitis, but the decision to perform a more-extended repair still requires surgical judgment at the time of the initial operation. Clearly, aortic diameter is very important in this decision-making process, but the underlying pathology, the patient's potential for long-term survival, and the surgeon's experience must additionally be taken into consideration. Patients with diffuse aortic disease at high risk for disease progression should be referred to a center of excellence with documented outcomes and a program for life-long surveillance. ${ }^{5}$

The risk of stroke is of major concern in any arch operation. In all of these patients, the extent of proximal disease was such that hypothermic circulatory arrest was indicated, whether the creation of an ET was performed or not. Use of axillary artery cannulation and selective brain perfusion has been shown to have potential to help alleviate some of this risk. ${ }^{14,15}$ Although these techniques are now preferred in our practice, they were not necessarily preferred in our earlier experience. The number of events is not high enough to allow for a reliable statistical analysis of this risk, but only 3 of 7 patients who had a stroke had axillary cannulation; and 1 had antegrade brain perfusion. Despite our best efforts, some patient-related risk factors for stroke are unavoidable. ${ }^{16,17}$ Five of the 7 stroke patients had degenerative aneurysms with a very severe atheroma burden noted by the surgeon in the operative report.

Less-invasive thoracic endovascular aortic repair is increasingly being applied as the mode of stage 2 ET completion. ${ }^{4}$ The presence of an ET graft serves as an excellent substrate for the proximal landing zone during these procedures. The open approach was preferred when the disease extended to the thoracoabdominal segments, and during the early experience when thoracic endovascular aortic repair was not widely available. The endovascular ET completion technique was more frequently performed during the latter half of the experience, and has become the preferred method in patients with feasible anatomy, especially for those considered high risk for open replacement. In patients with dissection, thoracic endovascular aortic repair has been shown to offer some additional safety benefits for patients developing acute descending aortic complications. ${ }^{18,19}$

One limitation of this approach is the risk of pseudocoarctation, particularly in patients with chronic dissection and a narrow true lumen. This complication occurred in 1 patient $(0.8 \%)$, and it was managed with early, open stage 2 completion. To minimize this risk, we typically have used a shorter graft, or performed a long fenestration into the upper descending aorta. More recently, we have used the alternative strategy of placing a stent graft into the descending aorta as the frozen ET procedure for patients with chronic dissection who are at risk of kinking 
the conventional ET graft. ${ }^{20}$ After deploying the stent graft into the true lumen, it is sutured on the proximal end to the native aorta and the more-proximal surgical graft. This graft offers the advantage of true lumen expansion in the setting of chronic dissection. Further studies are needed to assess the safety and effectiveness of this alternative approach.

Limitations of this study include the retrospective analysis; and specific details regarding cause of death were incomplete. The follow-up is limited, and some patients were lost to follow-up. Nonetheless, this analysis provides important insights for management of moderately dilated descending aorta when it is encountered in the setting of proximal aortic disease that requires surgery.

In summary, our data support the placement of a prophylactic stage $1 \mathrm{ET}$, particularly in patients with chronic dissection, aortitis, or a connective tissue disorder with a moderately dilated descending aorta. This strategy is safe and effective and provides an advantage for managing late descending aortic complications and disease progression.

\section{Conflict of Interest Statement}

Authors have nothing to disclose with regard to commercial support.

You can watch a Webcast of this AATS meeting presentation by going to: http://webcast.aats.org/2015/Video/Tuesday/ 04-28-15_612_1629_Idrees.mp4

\section{References}

1. Svensson LG, Kim KH, Blackstone EH, Alster JM, McCarthy PM, Greenberg RK, et al. Elephant trunk procedure: newer indications and uses. Ann Thorac Surg. 2004;78:109-16; discussion 109-16.

2. Svensson LG. The elephant trunk procedure: uses in complex aortic diseases. Curr Opin Cardiol. 2005;20:491-5.

3. Svensson LG, Rushing GD, Valenzuela ES, Rafael AE, Batizy LH, Blackstone EH, et al. Modifications, classification, and outcomes of elephanttrunk procedures. Ann Thorac Surg. 2013;96:548-58.

4. Roselli EE, Subramanian S, Sun Z, Idrees J, Nowicki E, Blackstone EH, et al. Endovascular versus open elephant trunk completion for extensive aortic disease. J Thorac Cardiovasc Surg. 2013;146:1408-16; discussion 1416-7.

5. Hiratzka LF, Bakris GL, Beckman JA, Bersin RM, Carr VF, Casey DE Jr, et al. ACCF/AHA/AATS/ACR/ASA/SCA/SCAI/SIR/STS/SVM guidelines for the diagnosis and management of patients with Thoracic Aortic Disease: a report of the American College of Cardiology Foundation/American Heart Association Task Force on Practice Guidelines, American Association for Thoracic Surgery, American College of Radiology, American Stroke Association, Society of Cardiovascular Anesthesiologists, Society for Cardiovascular Angiography and Interventions, Society of Interventional Radiology, Society of Thoracic Surgeons, and Society for Vascular Medicine. Circulation. 2010;121:e266-369.

6. Elefteriades JA. Natural history of thoracic aortic aneurysms: indications for surgery, and surgical versus nonsurgical risks. Ann Thorac Surg. 2002;74: S1877-80; discussion S92-8

7. Roselli EE, Sepulveda E, Pujara AC, Idrees J, Nowicki E. Distal landing zone open fenestration facilitates endovascular elephant trunk completion and false lumen thrombosis. Ann Thorac Surg. 2011;92:2078-84.

8. Greenberg RK, Haddad F, Svensson L, O'Neill S, Walker E, Lyden SP, et al. Hybrid approaches to thoracic aortic aneurysms: the role of endovascular elephant trunk completion. Circulation. 2005;112:2619-26.

9. Roselli EE, Loor G, He J, Rafael AE, Rajeswaran J, Houghtaling PL, et al. Distal aortic interventions after repair of ascending dissection: the argument for a more aggressive approach. J Thorac Cardiovasc Surg. 2015;149(2 Suppl):117-24.e3.
10. LeMaire SA, Price MD, Parenti JL, Johnson ML, Lay AD, Preventza O, et al Early outcomes after aortic arch replacement by using the Y-graft technique Ann Thorac Surg. 2011;91:700-7; discussion 707-8.

11. Estrera AL, Sandhu HK, Miller CC, Charlton-Ouw K, Nguyen TC, Afifi RO, et al. Repair of extensive aortic aneurysms: a single-center experience using the elephant trunk technique over 20 years. Ann Surg. 2014;260:510-6; discussion 517-8.

12. Preventza O, Garcia A, Cooley DA, Tuluca A, Simpson KH, Bakaeen FG, et al Reoperations on the total aortic arch in 119 patients: short- and mid-term outcomes, focusing on composite adverse outcomes and survival analysis. $J$ Thorac Cardiovasc Surg. 2014;148:2967-72.

13. Kondoh H, Taniguchi K, Funatsu T, Toda K, Masai T, Takahashi T, et al. Total arch replacement with long elephant trunk anastomosed at the base of the innominate artery: a single-centre longitudinal experience. Eur J Cardiothorac Surg. 2012;42:840-8; discussion 848.

14. Svensson LG, Blackstone EH, Rajeswaran J, Sabik JF III, Lytle BW, GonzalezStawinski G, et al. Does the arterial cannulation site for circulatory arrest influence stroke risk? Ann Thorac Surg. 2004;78:1274-84.

15. Okita Y, Miyata H, Motomura N, Takamoto S. Japan Cardiovascular Surgery Database Organization. A study of brain protection during total arch replacement comparing antegrade cerebral perfusion versus hypothermic circulatory arrest, with or without retrograde cerebral perfusion: analysis based on the Japan Adult Cardiovascular Surgery Database. J Thorac Cardiovasc Surg. 2015;149(2 Suppl):S65-73.

16. Kim J, Choi SI, Park KH, Chun EJ, Lim C. Clinical significance of intraluminal atheroma in patients with ascending and arch aneurysm. Ann Thorac Surg. 2014 97:2034-40.

17. Javadikasgari H, Gillinov AM. Continuous evolution of risk assessment methods for cardiac surgery and intervention. Nat Rev Cardiol. 2015;12:440.

18. Hughes GC, Daneshmand MA, Swaminathan M, Nienaber JJ, Bush EL, Husain AH, et al. "Real world" thoracic endografting: results with the Gore TAG device 2 years after U.S. FDA approval. Ann Thorac Surg. 2008;86: 1530-7; discussion 1537-8.

19. Heijmen R, Fattori R, Thompson M, Dai-Do D, Eggebrecht H, Degrieck I, et al Mid-term outcomes and aortic remodelling after thoracic endovascular repair for acute, subacute, and chronic aortic dissection: the VIRTUE Registry. Eur J Vasc Endovasc Surg. 2014;48:363-71.

20. Lima B, Roselli EE, Soltesz EG, Johnston DR, Pujara AC, Idrees J, et al Modified and "reverse" frozen elephant trunk repairs for extensive disease and complications after stent grafting. Ann Thorac Surg. 2012;93:103-9; discussion 109.

Key Words: aneurysm, ascending aorta, stroke, surgery, complications, aortic operation, outcomes

\section{Discussion}

Dr Scott LeMaire (Houston, Tex). Dr Chad Hughes was the invited discussant. He regrets that he is unable to attend today, but he sent me his comments based on reading your manuscript in advance. I will read these for him today.

The authors present a series of 117 patients with predominantly proximal aortic disease who underwent "prophylactic" stage 1 elephant trunk (ET) repairs despite having only moderate distal aortic dilation, with a mean diameter of 4 $\mathrm{cm}$. They are to be commended on an outstanding mortality rate of $<1 \%$ in this mostly elective population; however, the stroke rate was not insignificant at $6 \%$. A total of $45 \%$ of the patients went on to stage 2 repair during a mean follow-up period of 4 years. The authors conclude that prophylactic stage 1 ET repair is a safe and effective strategy for longterm management of a moderately dilated descending 
thoracic aorta in patients with proximal aortic disease that requires aortic replacement.

I have several questions for the authors, to open the discussion of this paper. As you state in the introduction of the paper, current guidelines recommend descending thoracic aortic replacement when the aortic diameter is $>5.5$ to $6 \mathrm{~cm}$, yet the mean diameter at the time of stage 2 repair was only $5 \mathrm{~cm}$ in this series. Is it possible that the fact that an ET had been created biased the surgeons toward proceeding with stage 2 repair sooner than they might have otherwise? This possibility might especially be true for patients undergoing endovascular stage 2 completion.

Dr Jahanzaib Idrees (Cleveland, Ohio). Thank you, Dr LeMaire, and I want to thank to Dr Hughes for his comments and questions.

In at least $20 \%$ of the patients who completed stage 2 , the indications were acute, and some dynamic change occurred in the aortic pathology, such as rupture, chronic dissection, and rapid growth. So in these patients, the descending aortic diameter was a bit smaller, which slightly lowered the overall mean. In the majority of patients, the descending diameter was $>5 \mathrm{~cm}$ at the time of stage 2 completion.

Dr LeMaire. Okay. Thank you.

The second question relates to the major pitfall of total aortic arch replacement, compared with the more-limited hemi- or proximal arch replacement: the excess stroke rate. In this series of generally nonemergent cases, the stroke rate was $6 \%$, which is far greater than the $<1 \%$ to $2 \%$ stroke rate reported by many centers of excellence for elective hemiarch replacement.

Could the authors please comment on the possibility that when applied to large populations of patients, especially outside of centers of excellence, this excess neurologic morbidity may offset any potential mitigation of risk for stage 2 repair, given that the elective stage 2 repair may be performed with very low rates of morbidity and mortality in experienced centers in the modern era, even in the absence of a pre-existing ET graft?

Dr Idrees. I agree with Dr Hughes' observations. It was also concerning for us, and we went back and specifically reviewed those 7 patients who had the complication of stroke. We noticed that these patients had patient-specific risk factors that predisposed them for this postoperative complication.

As I mentioned before during my presentation, 5 of the 7 stroke patients had extensive atheromatous disease in the arch and descending aorta. In addition, a significant proportion of these patients were operated on during the earlier part of our experience, so in those cases of stroke, antegrade brain perfusion was used less frequently, and at the same time, the axillary artery cannulation was additionally used in only 3 patients. Both of these strategies are now routinely applied in our current practice, and likely as a result, the risk of stroke is lower in our recent experience.
Regarding Dr Hughes' comment about the comparison with hemiarch repair as a low-risk alternative, and whether these patients might be better off with limited initial repair, owing to a potentially lower risk of stroke: I would argue that in the current series on hemiarch repair, reporting a stroke risk of $1 \%$ to $2 \%$, patients are likely to have morelimited disease, with less involvement of the arch and descending aorta, compared with the patient population in our cohort. At the same time, if we were to perform a hemiarch repair in these 7 patients, these patients likely would still end up having the complication of postoperative stroke, because the risk of stroke in these patients was really a result of specific predisposing factors. In addition, a substantial proportion of patients in our series had undergone previous type A repair with ascending/hemiarch, and had presented with subsequent degeneration of the arch and descending aorta. In these patients, a total arch ET was the ideal procedure of choice.

In summary, I would say that the occurrence of stroke in our experience was associated with patient-specific risk factors. I do not think that these patients are at much higher risk of stroke because of the procedure.

Dr LeMaire. Dr Svensson—did you want to comment?

Dr Lars G. Svensson (Cleveland, Ohio). Do you want to finish your questions first? Then I will comment.

Dr LeMaire. I will ask just 1 more, in the interest of time.

One of the major limitations of this retrospective observational study is the lack of a control group of patients with similar, predominantly proximal aortic pathology and modest distal dilation who were treated using a morelimited proximal aortic operation followed by a stage 2 distal repair. Have you considered finding a similar cohort of patients from the large Cleveland Clinic aortic database to do a propensity-matched analysis examining long-term survival, to see if performing a prophylactic ET operation actually provides survival benefit compared with a morelimited initial proximal repair, when applied to a large population of these patients?

Dr Idrees. I agree with Dr Hughes that it is an interesting question to explore. However, it is very difficult to identify the patients who have a moderately dilated descending aorta and are getting either a stage 1 ET or a hemiarch repair. With the current available data, it will not be possible to identify that specific cohort to use for a comparison with the prophylactic stage 1 ET patients. The goals of our study were to characterize the patients who underwent prophylactic stage $1 \mathrm{ET}$, see what happens to them long term, and better understand the indications that lead to stage 2 completion in this cohort.

Dr Svensson. Thank you. So, a couple of things to emphasize from Dr Idrees' very good presentation: first, there was a very high incidence of patients with aortitis in this study. In addition, we know from previous experience, 
particularly with the giant cell arteritis patients, not so much in Takayasu's, but especially the giant cells, that over time they will develop aneurysmal disease of the descending aorta. So, although the aortas may not have been so large when we did them, we knew that probably over time that would evolve and potentially become a situation in which they would rupture.

The other group of patients that is, proportionally, I think, a bigger group of these patients, although it is not entirely clear, is those who have connective tissue disorders, ie, Loeys-Dietz and Marfan patients. So we tend to operate on those, first of all, with an ET procedure, because they often have had a previous operation. This approach is mostly for chronic dissection, and that prepares the way for the stage 2 operation.

For the stage 2 procedure, I think we probably should begin thinking about relaxing the indication criteria relating to size of the aorta. Given that I was the person who chaired the committee that wrote the guidelines, I think it is reasonable to say that with improved results-for example, those in this study - we maybe should be thinking, particularly in the patients with connective tissue disorders, about taking that size threshold down to approximately $5 \mathrm{~cm}$, particularly with the option of stenting.

The other large group of patients was those who had previous acute dissection. We were doing the arch redo for size or, for example, combined aortic valve regurgitation with the idea that we would afterward do a stage 2 ET, so we would rather do that arch and then do the stage 2 ET.

I realize that that approach is a bit different from the Crawford teaching, and I am not sure where Dr Coselli stands on this point, but perhaps you can answer that question: Should one leave the arch that is dissected and do this descending thoracotomy and put in a reverse ET at that time, or rather do a stage 1 ET and then the descending or thoracoabdominal repair as a second operation?

Perhaps you can comment on that. Those are some aspects of Dr Idrees' presentation to emphasize.
Dr LeMaire. To respond to your question-I think it depends on the patient and the pathology and the symptomatology of the patient. We have used both approaches, performing the arch first with convectional ET or the descending with reverse ET first, either prophylactically or in planning for an operation in the near future.

But for those patients with symptomatic or substantially larger thoracoabdominal aneurysms who are going to need replacement of the arch at a later date, we have used the reverse ET approach. It depends on the patient's situation.

Dr Svensson. Yes, I agree. Clearly, if the patient is symptomatic for the descending aorta, which obviously these patients were not, we would obviously do the thoracotomy, the descending first, and then put a reverse ET and deal with the arch later. Thank you.

Dr Anthony L. Estrera (Houston, Tex). Real quick, Lars. So at the Cleveland Clinic, you will do the prophylactic ET. On what size descending thoracic aorta are you going to do a prophylactic ET?

So, in my mind, I think that with anything $>4 \mathrm{~cm}$, I would start thinking about doing a prophylactic ET.

Dr Svensson. I agree. It depends what the underlying disease is. If a descending aorta is already $4 \mathrm{~cm}$, and you are dealing with an aortitis patient, particularly a giant cell aortitis patient, the aorta in those patients will enlarge over time. So for those patients, I like to have the ET in place.

The last thing I want to have to do is go back into the arch with deep hypothermic circulatory arrest and perform a thoracoabdominal type of reoperation, going into the arch in those patients. That is why I like to have that prophylactic ET available for the later likely thoracoabdominal or descending repair.

With the dissections, I am not quite so, perhaps, aggressive. But once again, if it is a young patient with a connective tissue disorder, especially if I have already done a debranching of the arch and I want to do a complete repair for this patient eventually, I will put in a prophylactic ET in those 2 patients at approximately 4.0 to $4.5 \mathrm{~cm}$. 